\title{
Fisetin Reduces Cell Viability Through Up-Regulation of Phosphorylation of ERK1/2 in Cholangiocarcinoma Cells
}

\author{
NAYOUNG KIM ${ }^{1}$, SANG HYUB LEE ${ }^{2}$, JUN HYUK SON ${ }^{2}$, JAE MIN LEE ${ }^{3}$, MIN-JUNG KANG ${ }^{1}$, \\ BO HYE KIM ${ }^{1}$, JUNG-SU LEE ${ }^{1}$, JI KON RYU ${ }^{2}$ and YONG-TAE KIM ${ }^{2}$ \\ ${ }^{1}$ Department of Convergence Medicine \& Asan Institute for Life Sciences, Asan Medical Center, \\ University of Ulsan College of Medicine, Seoul, Republic of Korea; \\ ${ }^{2}$ Department of Internal Medicine and Liver Research Institute, Seoul National University Hospital, \\ Seoul National University College of Medicine, Seoul, Republic of Korea; \\ ${ }^{3}$ Department of Internal Medicine, Gyeongsang National University College of Medicine, \\ Gyeongsang National University Changwon Hospital, Changwon, Republic of Korea
}

\begin{abstract}
Background: Cholangiocarcinoma (CCA) is a malignancy with poor prognosis and limited therapeutic options. Effective prevention and treatment of CCA require developing novel anticancer agents and improved therapeutic regimens. As natural products are concidered a rich source of potential anticancer agents, we investigated the anticancer effect of fisetin in combination with gemcitabine. Materials and Methods: Cytotoxic effect of fisetin and gemcitabine on a human CCA cell line SNU-308 was assessed by 3-(4,5dimethylthiazol-2-yl)-2,5-diphenyltetrazolium bromide assay and apoptosis assay using propidium iodine and annexin $V$. Molecular mechanisms of fisetin action in CCA were investigated by western blotting. Results: Fisetin was found to inhibit survival of CCA cells, through strongly phosphorylating ERK. It also induced cellular apoptosis additively in combination with gemcitabine. Expression of cellular proliferative markers, such as phospho-p65 and myelocytomatosis (MYC), were reduced by fisetin. Conclusion: These results suggest fisetin in combination with gemcitabine as a candidate for use in improved anticancer regimens.
\end{abstract}

Cholangiocarcinoma (CCA) is the second most common primary hepatic malignancy worldwide $(1,2)$. Surgical resection is the only effective therapeutic option for CCA, but this is applicable in fewer than $50 \%$ of cases because this

Correspondence to: Sang Hyub Lee, MD, Ph.D., Department of Internal Medicine, Seoul National University Hospital, Seoul National University College of Medicine, 101 Daehak-ro, Jongnogu, Seoul, 110-744, Korea. Tel: +82 220724892,Fax: +82 27629662, e-mail: gidoctor@snuh.org

Key Words: Fisetin, anticancer, gemcitabine, combinatory treatment, cholangiocarcinoma. type of cancer is mostly diagnosed at a late stage. Currently, there are no curative medical therapies for CCA. Targeted therapies have failed or shown only marginal benefits in several clinical trials with different drugs alone or in combination with chemotherapy (3-5). The development of effective targeted therapies in CCA is challenging because of the underlying genetic variability of the disease and the remarkable resistance of CCA cells to drug cytotoxicity (6). Systemic chemotherapy is increasingly being applied in cases of advanced CCA. One combination treatment is gemcitabine with cisplatin (7). The median overall survival with cisplatin plus gemcitabine was found to be significantly greater compared with that using gemcitabine alone (11.7 versus 8.1 months), however, it is not curable only palliative (7). Furthermore, combination treatment contributes to added toxicity and strong drug resistance (8-11).

Novel strategies for sensitizing tumor cells with naturallyoccurring dietary chemopreventive compounds have gained considerable attention because of their beneficial effects in overcoming tumor cell resistance to apoptosis (12). Soy isoflavones including genistein, daidzein, and glycitein, mainly derived from soybeans, have been found to inhibit breast cancer growth in vivo and in vitro (13). Indole-3-carbinol and its in vivo dimeric product diindolylmethane, produced from naturally occurring glucosinolates in the Cruciferase family, have been shown to inhibit prostate cancer cell growth through the modulation of genes related to the control of cell proliferation, cell cycle, apoptosis, signal transduction, oncogenesis, and transcription regulation (14). One flavonoid, apigenin, is widely distributed in many fruits and vegetables, and has been shown to exert anti-inflammatory and anticancer effects alone and in combination with gemcitabine $(15,16)$. Guggulsterone (4,18[20]-pregnadiene-3,16-dione), a polyphenol from Commiphora mukul., also increased apoptosis of pancreatic cancer cells in combination with gemcitabine (17). 
Fisetin (3,3', $4^{\prime}, 7$-tetrahydroxyflavone) is a bioactive flavone present in various fruits and vegetables, including strawberry, grape, apple, onion, and cucumber (18). Dietary fisetin is believed to have a number of health-promoting effects that include antioxidant, anticarcinogenic, antiprolifertive and apoptotic activities (19). Fisetin is cytotoxic towards non-small cell lung (20), colon (21-22), prostate (23) and pancreatic (24) cancer cells, as well as malignant melanoma cells (25). Fisetin causes cell-cycle arrest through the inhibition of Aurora B kinase directly in several cancer types (26). In addition, fisetin down-regulates nuclear factor $\mathrm{kB}$ (NF-kB) via mitogen-activated protein kinase signaling pathways during cancer metastasis $(27,28)$.

Rat sarcoma (RAS)-extracellular signal-regulated kinase (ERK) (29) and phosphoinositide 3-kinase (PI3K)-AKR mouse thymoma kinase (AKT) (30) signaling pathways play central roles in multiple processes associated with cancer. The RAS-ERK signaling axis stimulates cell proliferation and the PI3K-AKT signaling axis promotes cell survival. Genetic alterations in critical components in these pathways result in unrestricted cellular proliferation and reducedsensitivity to chemotherapies in cancer. Controlling these pathways using inhibitors is a key therapeutic target for cancer therapy.

In this study, we investigated the effect of fisetin on a human CCA cell line, SNU-308. We also explored the action mechanisms of fisetin on CCA and of the potential combination treatment using fisetin and gemcitabine.

\section{Materials and Methods}

Cell culture and reagents. SNU-308, a human CCA cell line, was obtained from the Korean Cell Line Bank (Seoul, Korea). SNU-308 cells were grown in Roswell Park Memorial Institute 1640 (RPMI1640; Welgene, Gyeongsan, Korea) with $1 \%$ streptomycin and penicillin (Corning, Corning, NY, USA), $5 \mathrm{mM}$ sodium pyruvate (PAN BIOTECH, Aidenbach, Germany) and $10 \%$ fetal bovine serum (FBS; Tissue Culture Biologicals, Tulare, CA, USA). The cells were maintained under standard cell culture conditions at $37^{\circ} \mathrm{C}$ and $5 \% \mathrm{CO}_{2}$ in a humid environment. For experiments, cells were seeded in $60 \mathrm{~mm}$ culture dishes $\left(4 \times 10^{5}\right.$ cells/dish), and allowed to attach overnight. Compounds (200 $\mu \mathrm{M}$ fisetin with/without $150 \mu \mathrm{M}$ gemcitabine) were added, and the cells were incubated for 16, 24, 48 or $72 \mathrm{~h}$. Cells were treated with Dimethyl sulfoxide (DMSO) $(0.25 \%)$ as vehicle control.

3(4,5-Dimethylthiazol-2yl)-2,5diphenyltetrazolium bromide (MTT) assay. Cells were seeded on 96-well plates containing a final volume of $100 \mu \mathrm{l} /$ well at a density of $4 \times 10^{3}$ cells/well, incubated at $37^{\circ} \mathrm{C}$ for $24 \mathrm{~h}$ and then treated with $200 \mu \mathrm{M}$ fisetin alone and with $150 \mu \mathrm{M}$ gemcitabine for 24,48 , and $72 \mathrm{~h}$. In order to determine the live cell numbers, $10 \mu \mathrm{l}$ of $5 \mathrm{mg} / \mathrm{ml}$ MTT (Promega, Madison, WI, USA) in phosphate-buffered saline (PBS) was added to the cells and allowed to develop for $1 \mathrm{~h}$ at $37^{\circ} \mathrm{C}$. To dissolve formazan crystals, $100 \mu \mathrm{l}$ of $10 \%$ sodium dodecyl fulfate (SDS) solution was added to cells and they were incubated overnight at room temperature (RT).
The solution was mixed to ensure complete solubilization. Colorimetric measurements were taken at $570 \mathrm{~nm}$ by a Sunrise ${ }^{\mathrm{TM}}$ reader (Tecan, Mannedorf, Switzerland).

Apoptosis assay. Apoptosis was examined using a double-staining method with allophycocyanin (APC)-labeled annexin-V (AV) and propidium iodide (PI) Apoptosis Detection kit (BD Biosciences, Franklin Lakes, NJ, USA). For PI and AV staining, cells $\left(1 \times 10^{5}\right)$ were suspended with $100 \mu \mathrm{l}$ of Annexin-binding buffer (BD Biosciences). Cell suspension was stained with $5 \mu$ of APCconjugated AV and $5 \mu \mathrm{l}$ of PI for $15 \mathrm{~min}$ at RT and then $400 \mu \mathrm{l}$ of annexin-binding buffer was added. Apoptotic and necrotic cells were analyzed with a flow cytometer (FACScanto II; BD Biosciences). Data analysis was performed with FlowJo software (FlowJo LLC, Ashland, OR, USA).

Protein extraction and western blot analysis. Cells were harvested after treatment of fisetin with/without gemcitabine for $16 \mathrm{~h}$, washed twice in PBS and then suspended in $20 \mu$ of lysis buffer $(50 \mathrm{mM}$ Tris- $\mathrm{HCl}$ at $\mathrm{pH}$ 8.0, $5 \mathrm{mM}$ EDTA, $150 \mathrm{mM} \mathrm{NaCl}, 1 \% \mathrm{NP}-40,1 \mathrm{mM}$ phenylmethylsulfonyl fluoride, $0.1 \%$ SDS, Protease Inhibitor cocktails (Roche, Basel, Switzerland), $5 \mathrm{mM} \mathrm{NaF}, 2 \mathrm{mM} \mathrm{Na} \mathrm{VO}_{4}$ ). Cell suspensions were kept on ice for $15 \mathrm{~min}$ and then centrifuged at $13,500 \times \mathrm{g}$ at $4^{\circ} \mathrm{C}$ for $15 \mathrm{~min}$. Protein concentrations were determined by the BCA Protein Assay kit (Thermo Fisher Scientific, Waltham, MA, USA) following the manufacturers' instructions. An equal amount $(30 \mu \mathrm{g})$ of each protein sample was loaded into each lane, separated by SDS-polyacrylamide gel electrophoresis (PAGE) on $10 \%$ polyacrylamide gradient, and then transferred onto polyvinylidene difluoride membrane (Amersham Biosciences, Amersham, UK). Membranes were blocked with $3 \%$ bovine serum albumin in PBS containing 1\% Tween-20 (PBS-T) for 30 min at RT and followed by incubation with primary antibodies overnight at $4^{\circ}$. Membranes were washed three times in PBS-T and incubated for $1 \mathrm{~h}$ at RT with horseradish peroxidase-conjugated secondary antibody. Bands were visualized using an enhanced chemilumi-nescence detection system (ImageQuant LAS 4000; GE Healthcare, Uppsala, Sweden). Antibodies against phospho-AKT (monoclonal), AKT (polyclonal), phospho-ERK (monoclonal), ERK (monoclonal), and beta-actin (monoclonal)were purchased from Cell Signaling Technology, Inc. (Danvers, MA, USA). horseradish peroxidaseconjugated secondary antibody, phospho-p65 (monoclonal) and p65 (polyclonal) were purchased from Santa Cruz Biotechnology (Dallas, TX, USA).Quantification of band intensity was assessed with Image StudioTM Lite Ver. 5.2 (Li-COR Bioscience, Lincoln, NE, USA).

Quantification of mRNA of MYC. Total RNA was extracted using TRIzol $^{\mathrm{TM}}$ (Thermo Fisher Scientific) reagent following the manufacturer's instructions. The quantity and purity of total RNA were measured using an UV/Vis-Spectrophotometer (NanoDrop ND2000; Thermo Fisher Scientific). cDNA was synthesized with $2 \mu \mathrm{g}$ of total RNA using the SuperScript III reverse transcriptase (Invitrogen, Carlsbad, CA, USA) and oligo d(T) primers (Invitrogen). The amplification was performed in $20 \mu \mathrm{l}$, containing $1 \mu \mathrm{l}$ of each primer of 5 pM. SYBR Green PCR master mix (Applied Biosystems) and 2 $\mu \mathrm{l}$ of $1: 10$ diluted cDNA. Amplification conditions were $95^{\circ} \mathrm{C}$ for 10 $\mathrm{s}$, and $60^{\circ} \mathrm{C}$ for $1 \mathrm{~min}$ for 40 cycles. Primer sequences were as follows: $M Y C$ forward: 5'-AAA GGC CCC CAA GGT AGT TA-3', and reverse: 5'-TTT CCG CAA CAA GTC CTC TT-3' (31). Glyceraldehyde 3-phosphate dehydrogenase $(G A P D H)$ transcripts 
were amplified as a reference standard. GAPDH primers were as follows: forward: 5'-ACC CAG AAG ACT GTG GAT GG-3', and reverse: 5'-TTC AGC TCA GGG ATG ACC TT-3'. All primers were synthesized by Bioneer Co. (Daejeon, Korea).

Statistical methods. Statistical comparisons were made using the two-tailed Students' $t$-test using Excel software (Microsoft, Seatle, WA, USA). Results were considered significant in all experiments at $p<0.05$. Data are expressed as the mean \pm SEM.

\section{Results}

Fisetin reduces cell viability and induces apoptosis in combination with gemcitabine. The effect of fisetin alone and in combination with gemcitabine on survival and proliferation of SNU-308 cells was examined by the MTT assay at different incubation times $(24,48$ and $72 \mathrm{~h})$. The concentration of each agent was selected to produce moderate cell death, as we aimed to investigate additive or synergistic effects of both agents. The combinatory treatment of fisetin and gemcitabine reduced cell viability compared to a single treatments (Figure 1A). Survival of the cells treated with fisetin and gemcitabine in combination was reduced by $34.2 \%$ at $72 \mathrm{~h}$ compared to vehicle control, which was treated with DMSO. We tested the effect of fisetin on two other CCA cell lines (SNU-1079 and SNU1196) as well, and found that fisetin indeed reduced survival of both cell lines, but susceptibility depended on the cell line (data not shown).

To confirm apoptotic induction by fisetin and gemcitabine, cells were labeled with $\mathrm{AV}$ and PI. Fisetin alone induced apoptosis $\left(\mathrm{PI}^{-} / \mathrm{AV}^{+}\right.$early apoptotic cells and $\mathrm{PI}^{+} / \mathrm{AV}^{+}$late apoptotic/necrotic cells). Fisetin and gemcitabine used alone increased the proportion of early apoptotic cells (Figure 1B and C). Exposure to fisetin $(200 \mu \mathrm{M})$ with gemcitabine $(150 \mu \mathrm{M})$ further induced apoptosis, in up to $62.4 \%$ of SNU-308 cells, as seen in the representative result shown in Figure 1B. The combination treatment of fisetin and gemcitabine induced apoptosis more efficiently than gemcitabine alone (29.2\%). Taken together, fisetin reduced SNU-308 cell numbers by inducing apoptosis.

Fisetin induces activation of ERK1/2 and AKT. In order to determine which signaling pathways were affected by fisetin, immunoblotting was performed to detect ERK, phosphoERK, AKT and phospho-AKT. In addition, immunoblotting for p65 and phospho-p65 was performed to test whether fisetin affected the NF-kB pathway in SNU-308 cells. Interestingly, fisetin alone strongly induced phosphorylation of ERK1/2, and phospho-AKT appeared to increase by fisetin, although the difference was not significant (Figure 2). Fisetin reduced slightly, if at all, phosphorylation of p65, a subunit of NF-kB complex. Taken together, upregulation of ERK activation in RAS-ERK pathway by fisetin was most outstanding and might be the cause of reduced CCA cell viability. However, gemcitabine alone and combination of fisetin and gemcitabine did not further increase phosphorylation of AKT and ERK. Only NF-kB activation was increased by combinatory treatment. In conclusion, the effect of fisetin and gemcitabine on SNU-308 cell viability did not seem to be the result of additive stimulation of the same signaling pathways, and fisetin and gemcitabine may have distinct action mechanisms.

Fisetin down-regulates the expression of $c-M Y C$ at the transcription level. MYC, a transcription factor, is an important downstream target of RAS-ERK signaling. In order to address whether increased phosphorylation of ERK1/2 affected MYC expression, the mRNA level of MYC was assessed by quantitative reverse transcription polymerase chain reaction. The results from fisetin-treated cells showed 5-fold decrease in the mRNA level of the $M Y C$ gene (Figure 3), suggesting that fisetin down-regulated $M Y C$ expression not stimulated it. However, it should be mentioned that cotreatment of fisetin and gemcitabine did not affect $M Y C$ expression, as it did not affect phosphorylation of ERK. This result implies that cellular proliferation, which $M Y C$ promotes, might be blocked by fisetin.

\section{Discussion}

CCA is characterized by a poor prognosis, with a median survival of less than 24 months (32) and a limited response to chemotherapy. The number of clinical trials with targeted therapy alone and in combination with traditional chemotherapy is expanding for advanced-stage CCA. However, the major problem is due to treatment-associated toxicity with no significant added benefit in overall survival (7). Moreover, CCA is characterized by a remarkable resistance to common chemotherapy $(33,34)$. In order to overcome these limitations of current chemotherapeutic regimens, we evaluated the efficacy of fisetin, a nontoxic flavonoid compound, in combination with a common chemotherapeutic agent, gemcitabine, against SNU-308 CCA cells. This study documents that sensitization of cancer cells was achieved by fisetin during gemcitabine-induced killing, as shown by more pronounced cell death compared with single-agent treatment.

It is widely accepted that chemotherapy acts primarily through blocking the survival and proliferation signaling pathways of cancer cells, and that alteration in these signaling pathways can make cancer cells resistant to therapy (35). In particular, RAS-ERK and PI3K-AKT signaling pathways contribute to cancer proliferation and cell survival, respectively (35). In normal cells, these pathways are transiently activated in response to growth factors, cytokines and ligands of integrin, but genetic alterations can lead to constitutive signaling even in the absence of growth factors. 


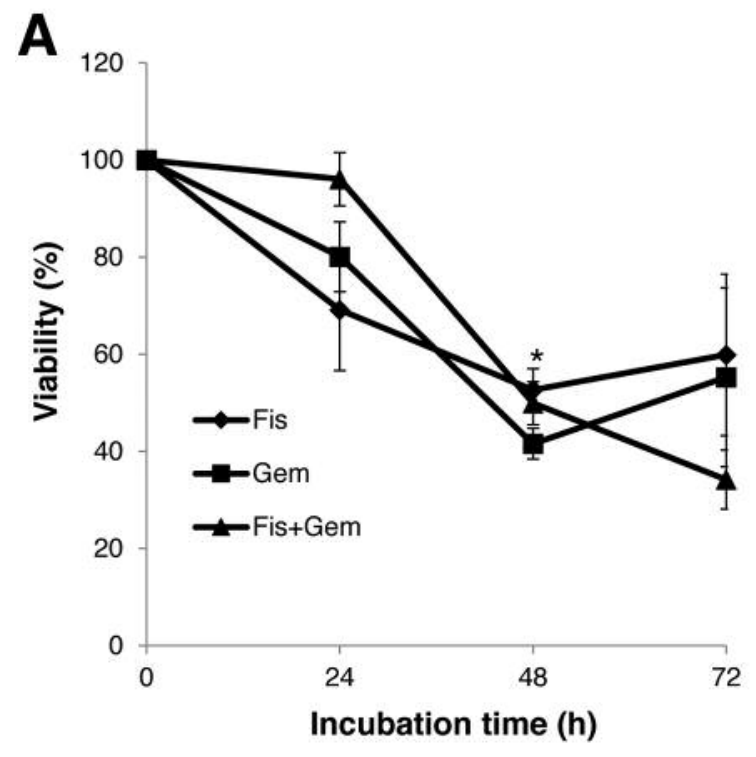

C

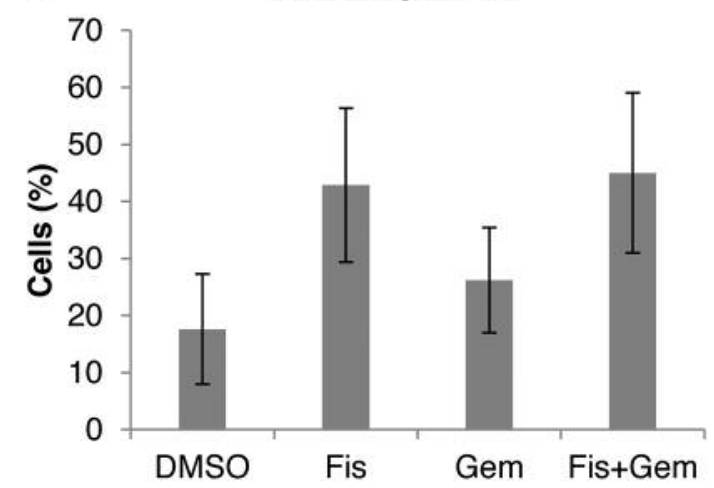

B

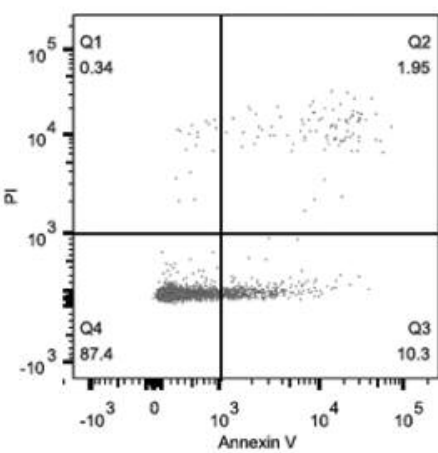

Gem

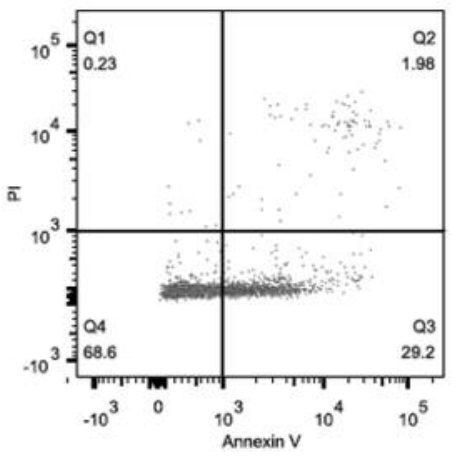

Fis

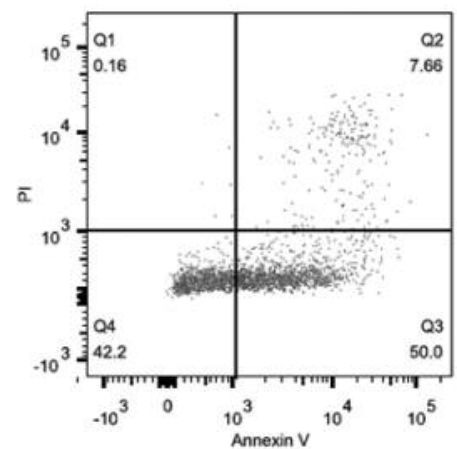

Fis+Gem

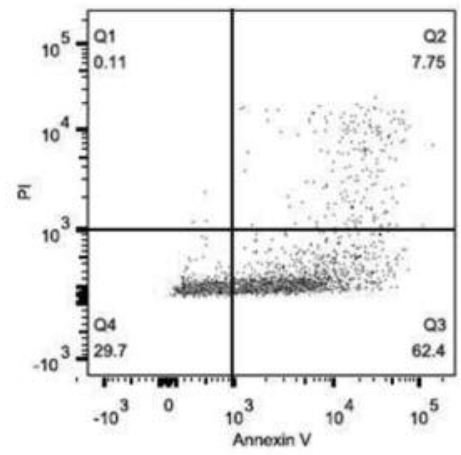

$\mathrm{PI}+/$ Annexin V+

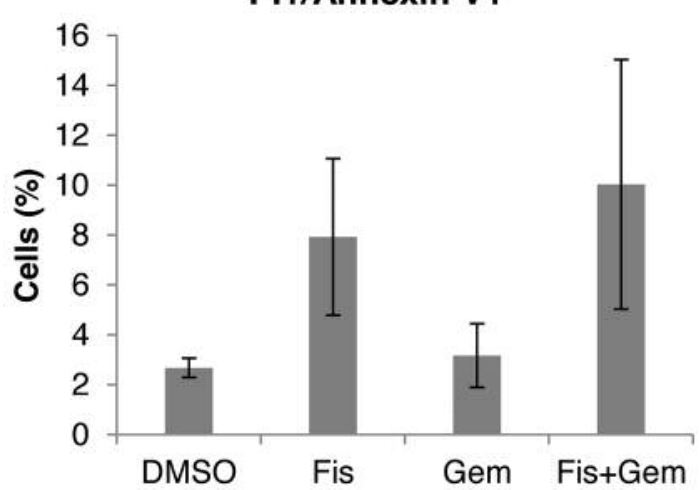

Figure 1. Fisetin (Fis) inhibits cell proliferation and induces apoptosis in combination with gemcitabine (Gem). A: 3-(4,5-Dimethylthiazol-2-yl)2,5-diphenyltetrazolium bromide assay showed that fisetin with/without gemcitabine inhibited the growth of SNU-308 cells in a time-dependent manner. The experiments were performed in triplicates and the graph is representative of three independent experiments. Data represent the means \pm SEM of triplicates. ${ }^{*} p<0.05$ between the fisetin-treated cells and the dimethyl sulfoxide (DMSO)-treated cells at $48 \mathrm{~h}$ by Student's t-test. B: SNU-308 cells were stained with allophycocyanin-conjugated annexin $V$ and propidium iodide (PI) and analyzed by flow cytometry after fisetin/gemcitabine treatment for $16 \mathrm{~h}$. C: Percentage of early apoptotic cells $\left(\mathrm{PI}^{-} /\right.$annexin $\left.\mathrm{V}^{+}\right)$and late apoptotic and necrotic cells $\left(\mathrm{PI}^{+} /\right.$annexin $\left.V^{+}\right)$are displayed in the graphs. Data represent the means \pm SEM of three independent experiments.

However, the role of ERK is controversial, considering that its activation can result in either cell proliferation or cell death. It is reported that the activation of ERK can be a result of DNA damage that subsequently leads to cell-cycle arrest and apoptosis $(36,37)$. In addition, ERK activation has been suggested to be a response to counteract endoplasmic reticulum stress-induced apoptosis $(38,39)$, induced by external stimuli such as cytotoxic agents. 
A
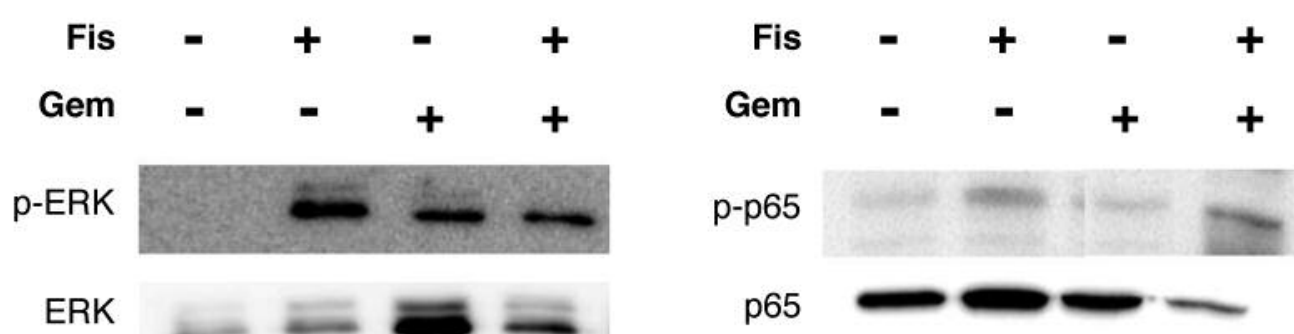

\section{ERK}

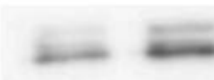

p-AKT

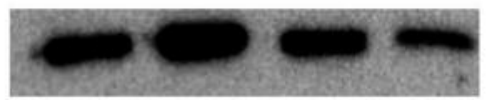

AKT

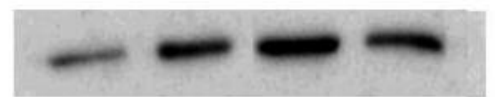

$\beta$-Actin
B

\section{p-ERK/ERK}

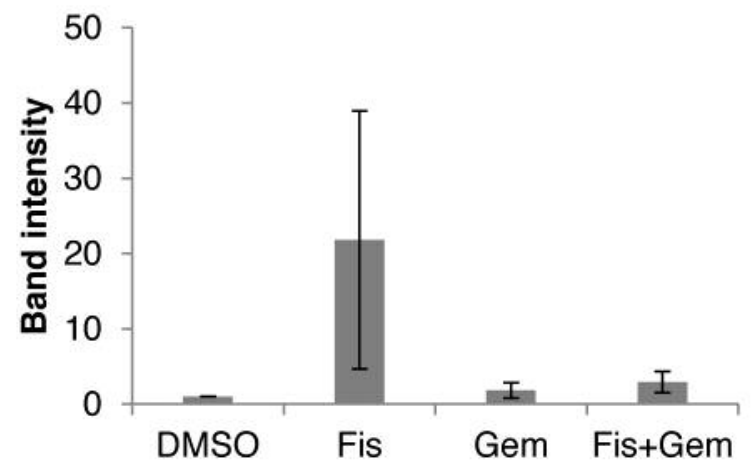

$\beta$-Actin

\section{p-AKT/AKT}

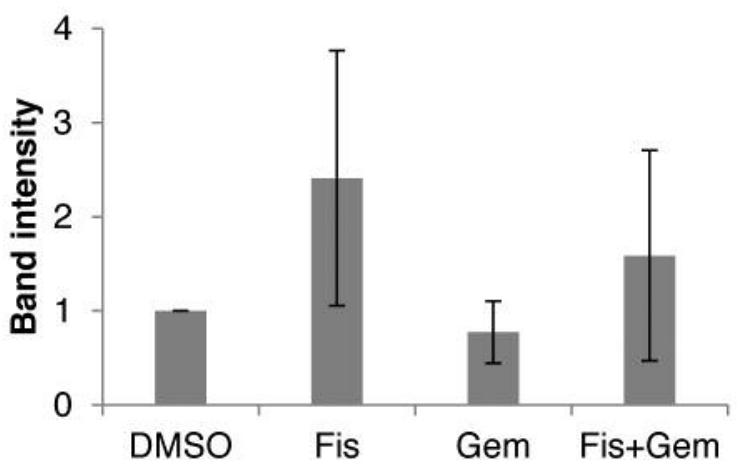

p-p65/p65

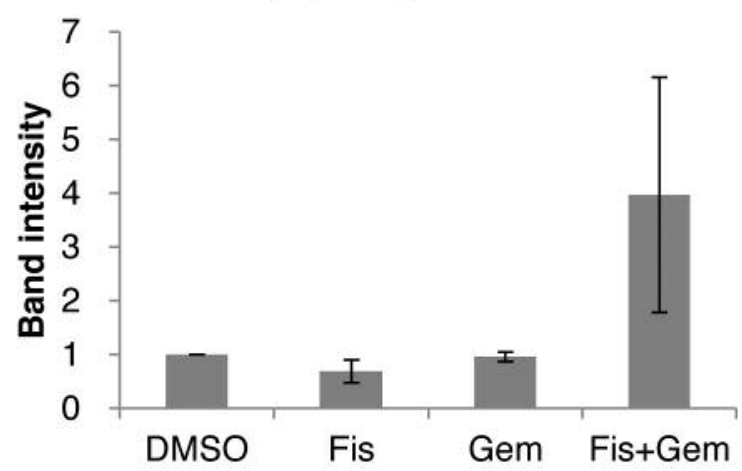

Figure 2. Fisetin (Fis)-induced apoptosisis mediated by phosphorylation of extracellular signal-regulated kinase 1/2 (ERK1/2). A: The protein levels of phospho-ERK, ERK, phospho-v-akt murine thymoma viral oncogene homolog (AKT), AKT, phospho-p65, p65 and $\beta$-actin were examined using sodium dodecyl sulfate-polyacrylamide gel electrophoresis gel electrophoresis and western blot analysis after $16 \mathrm{~h}$ of designated drug treatment. The results are representative of three independent experiments. B: Relative intensities of bands of phosphorylated proteins to total proteins are displayed in the graphs. Data represent the means \pm SEM of three independent experiments. Gem: Gemcitabine. 


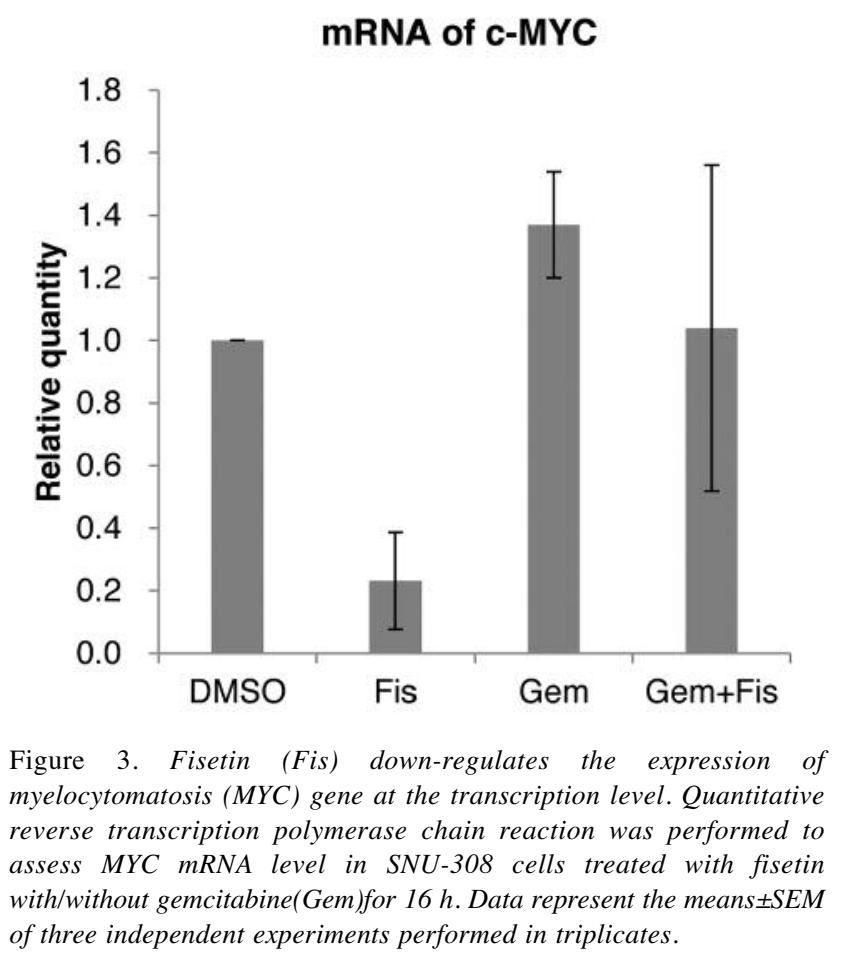

In this study, we found that fisetin induced strong phosphorylation of ERK1/2 and down-regulated MYC. The strong or sustained activation of mitogen-activated protein kinase pathways arrests the cell cycle, whereas transient activation induces cell-cycle progression (40). In line with these results, low levels of v-raf-1 murine leukemia viral oncogene homolog 1 (RAF1) activity induce cyclin D1 and therefore proliferation, whereas high levels lead to $p 21$ induction and growth arrest $(41,42)$. High levels of ERK1/2 activity as a result of fisetin treatment leads to $M Y C$ repression and therefore $p 21$ induction (21). The hypothetical mechanism of action of fisetin is depicted in Figure 4. Fisetin seems to lead to arrest of hypermitogenic cell cycle, increasing susceptibility to gemcitabine. Gemcitabine is an intravenous drug that in metabolized within tumor cells and induces a programmed cell death response by blocking the progression of dividing cells through the $G_{1} / S$ phase boundary (43). In general, gemcitabine treatment results in the accumulation of the phophorylated forms of checkpoint kinase 1 (CHK1) and CHK2 and degradation of cell division cycle 25A (43-45). It seems that gemcitabine-induced CHK1 activation functions in part to coordinate cell-cycle progression with DNA synthesis, preventing cells with stalled replication from prematurely entering mitosis (43). Thus, gemcitabinetreated cells are arrested in the early S-phase (43). It is likely that gemcitabine shifts cell-cycle arrest by fisetin via

\section{Fisetin}

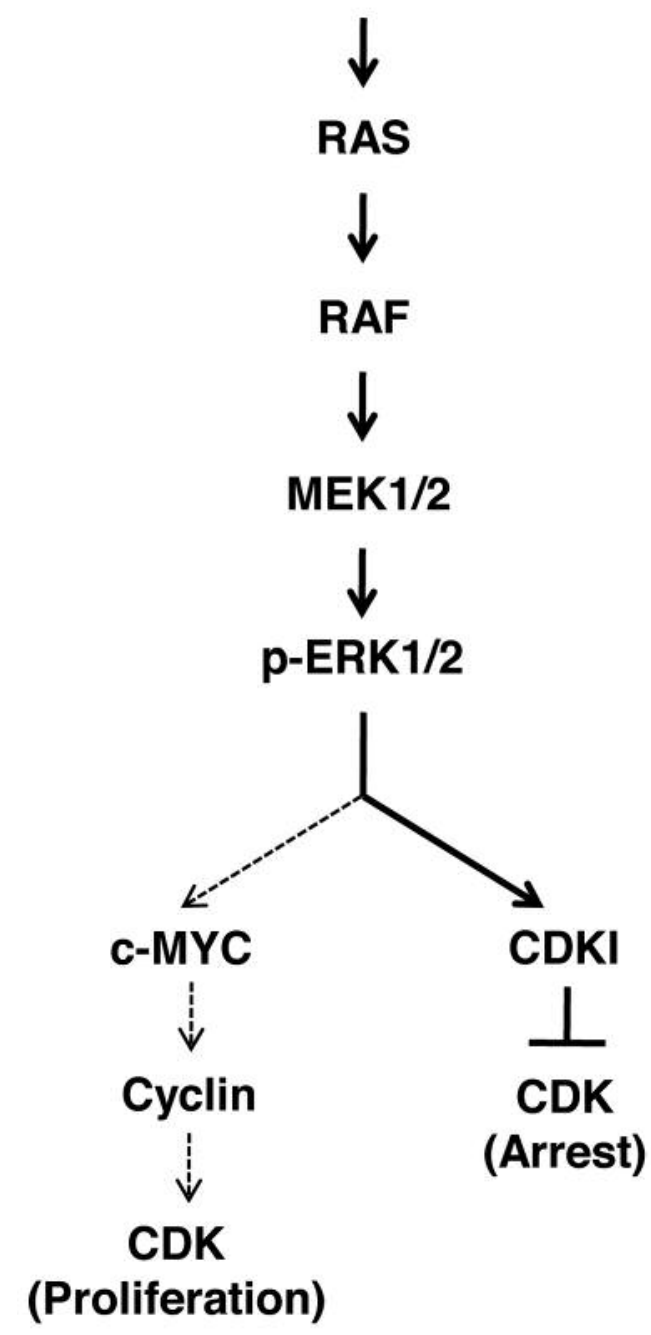

Figure 4. Schematic view of hypothetical model of action of fisetin showing that fisetin induces apoptosis of SNU-308 cholangiocarcinoma cells through up-regulation of phosphorylation of extracellular signalregulated kinase 1/2 (ERK1/2) in V-Ki-Ras 2 Kirsten rat sarcoma 2 viral oncogene homolog (RAS)- extracellular signal-regulated kinase (ERK) signaling pathway, and reduced myelocytomatosis (MYC) expression also contributes to reduced proliferation of cholangiocarcinoma (CCA) cells. MEK1/2: Mitogen-activated protein kinse 1/2; RAF: v-raf-1 murine leukemia viral oncogene homolog; CDK: cell cycle-dependent kinase.

ERK-dependent signaling pathway to apoptosis irreversibly $v i a$ an alternative signaling pathway. It is possible that dual treatment of fisetin and gemcitabine might induce apoptosis and inhibit cell proliferation, respectively, leading to an additive anticancer effect.

In conclusion, we demonstrated that fisetin seems to induce cell death through the RAS-ERK pathway and sensitization of cancer cells achieved by fisetin induces cell 
death through an alternative pathway by gemcitabine. These results imply that alternative pathways that control cell proliferation and survival might be prevented by combination treatment with fisetin and gemcitabine, making them attractive agents for CCA treatment.

\section{Acknowledgements}

N. Kim was supported by a grant from Asan Institute for Life Sciences, Asan Medical Center (Grant No. 12/13-556). S. H. Lee was supported by a grant from the Academic Scholarship of Seoul National University College of Medicine Alumni Association.The Authors are thankful to Ms. Sujeong Kim for technical support.

\section{References}

1 Anderson CD, Pinson CW, Berlin J and Chari RS: Diagnosis and treatment of cholangiocarcinoma. Oncologist 9: 43-57, 2004.

2 Razumilava N and Gores GJ: Cholangiocarcinoma. Lancet 383: 2168-2179, 2014.

3 Borbath I, Ceratti A, Verslype C, Demols A, Delaunoit T, Laurent S, Deleporte A, Vergauwe P, Van Maanen A, Sempoux C, Van Cutsem E and Van Laethem JL: Combination of gemcitabine and cetuximab in patients with advanced cholangiocarcinoma: a phase II study of the Belgian Group of Digestive Oncology. Ann Oncol 24: 2824-2829, 2013.

4 Lee J, Park SH, Chang HM, Kim JS, Choi HJ, Lee MA, Jang JS, Jeung HC, Kang JH, Lee HW, Shin DB, Kang HJ, Sun JM, Park JO, Park YS, Kang WK and Lim HY: Gemcitabine and oxaliplatin with or without erlotinib in advanced biliary-tract cancer: a multicentre, open-label, randomised, phase 3 study. Lancet Oncol 13: 181-188, 2012.

5 Yi JH, Thongprasert S, Lee J, Doval DC, Park SH, Park JO, Park YS, Kang WK and Lim HY: A phase II study of sunitinib as a second-line treatment in advanced biliary tract carcinoma: a multicentre, multinational study. Eur J Cancer 48: 196-201, 2012.

6 Zabron A, Edwards RJ and Khan SA: The challenge of cholangiocarcinoma: dissecting the molecular mechanisms of an insidious cancer. Dis Model Mech 6: 281-292, 2013.

7 Stuart KE: Systemic therapy for advanced cholangiocarcinoma. Available at: http://www.uptodate.com/contents/systemictherapy-for-advanced-cholangiocarcinoma

8 Giuliani F, Gebbia V, Maiello E, Borsellino N, Bajardi E, Colucci G and Gruppo Oncologico dell'Italia M: Gemcitabine and cisplatin for inoperable and/or metastatic biliary tree carcinomas: a multicenter phase II study of the Gruppo Oncologico dell'Italia Meridionale (GOIM). Ann Oncol 17(Suppl 7): vii73-77, 2006.

9 Okusaka T, Nakachi K, Fukutomi A, Mizuno N, Ohkawa S, Funakoshi A, Nagino M, Kondo S, Nagaoka S, Funai J, Koshiji M, Nambu Y, Furuse J, Miyazaki M and Nimura Y: Gemcitabine alone or in combination with cisplatin in patients with biliary tract cancer: a comparative multicentre study in Japan. Br J Cancer 103: 469-474, 2010.

10 Thongprasert S, Napapan S, Charoentum C and Moonprakan S: Phase II study of gemcitabine and cisplatin as first-line chemotherapy in inoperable biliary tract carcinoma. Ann Oncol 16: 279-281, 2005.
11 Valle JW, Wasan H, Johnson P, Jones E, Dixon L, Swindell R, Baka S, Maraveyas A, Corrie P, Falk S, Gollins S, Lofts F, Evans L, Meyer T, Anthoney A, Iveson T, Highley M, Osborne R and Bridgewater J: Gemcitabine alone or in combination with cisplatin in patients with advanced or metastatic cholangiocarcinomas or other biliary tract tumours: a multicentre randomised phase II study - The UK ABC-01 Study. Br J Cancer 101: 621-627, 2009.

12 Bharti AC and Aggarwal BB: Chemopreventive agents induce suppression of nuclear factor-kB leading to chemosensitization. Ann N Y Acad Sci 973: 392-395, 2002.

13 Barnes S: The chemopreventive properties of soy isoflavonoids in animal models of breast cancer. Breast Cancer Res $\operatorname{Tr} 46: 169-$ 179, 1997.

14 Chinni SR, Li Y, Upadhyay S, Koppolu PK and Sarkar FH: Indole-3-carbinol (I3C) induced cell growth inhibition, G1 cellcycle arrest and apoptosis in prostate cancer cells. Oncogene 20: 2927-2936, 2001.

15 Gupta S, Afaq F and Mukhtar H: Selective growth-inhibitory, cell-cycle deregulatory and apoptotic response of apigenin in normal versus human prostate carcinoma cells. Biochem Biophys Res Commun 287: 914-920, 2001.

16 Lee SH, Ryu JK, Lee KY, Woo SM, Park JK, Yoo JW, Kim YT and Yoon YB: Enhanced anti-tumor effect of combination therapy with gemcitabine and apigenin in pancreatic cancer. Cancer lett 259: 39-49, 2008.

17 Ahn DW, Seo JK, Lee SH, Hwang JH, Lee JK, Ryu JK, Kim YT and Yoon YB: Enhanced antitumor effect of combination therapy with gemcitabine and guggulsterone in pancreatic cancer. Pancreas 41: 1048-1057, 2012.

18 Kimira M, Arai Y, Shimoi K and Watanabe S: Janpanese intake of flavonoid and isoflavonoid from foods. J Epidemiol 8: 168$175,1998$.

19 Khan N, Syed DN, Ahmad N and Mukhtar H: Fisetin: a dietary antioxidant for health promotion. Antioxid Redox Signal 19: 151-162, 2013.

20 Khan N, Afaq F, Khusro FH, Mustafa Adhami V, Suh Y and Mukhtar H: Dual inhibition of phosphatidylinositol 3kinase/AKT and mammalian target of rapamycin signaling in human non-small cell lung cancer cells by a dietary flavonoid fisetin. Int J cancer 130: 1695-1705, 2012.

21 Lu X, Jung JI, Cho HJ, Lim DY, Lee HS, Chun HS, Kwon DY and Park HY: Fisetin inhibits the activities of cyclin-dependent kinase leading to cell cycle arrest in HT-29 human colon cancer cells. J Nutr 135: 2884-2890, 2005.

22 Suh Y, Afaq F, Johnson JJ and Mukhtar H: A plant flavonoid fisetin induces apoptosis in colon cancer cells by inhibition of COX2 and Wnt/EGFR/NF-kappaB-signaling pathways. Carcinogenesis 30: 300-307, 2009.

23 Khan N, Afaq F, Syed DN and Mukhtar H: Fisetin, a novel dietary flavonoid, causes apoptosis and cell-cycle arrest in human prostate cancer LNCaP cells. Carcinogenesis 29: 1049-1056, 2008.

24 Murtaza I, Adhami VM, Hafeez BB, Saleem M and Mukhtar H: Fisetin, a natural flavonoid, targets chemoresistant human pancreatic cancer AsPC-1 cells through DR3-mediated inhibition of NF-kappaB. Int J cancer 125: 2465-2473, 2009.

25 Syed DN, Afaq F, Maddodi N, Johnson JJ, Sarfaraz S, Ahmad A, Setaluri V and Mukhtar H: Inhibition of human melanoma cell growth by the dietary flavonoid fisetin is associated with disruption of WNT/beta-catenin signaling and decreased Mitf levels. J Invest Dermatol 131: 1291-1299, 2011. 
26 Salmela AL, Pouwels J, Varis A, Kukkonen AM, Toivonen P, Halonen PK, Perala M, Kallioniemi O, Gorbsky GJ and Kallio MJ: Dietary flavonoid fisetin induces a forced exit from mitosis by targeting the mitotic spindle checkpoint. Carcinogenesis 30: 1032-1040, 2009.

27 Chien CS, Shen KH, Huang JS, Ko SC and Shih YW: Antimetastatic potential of fisetin involves inactivation of the $\mathrm{PI} 3 \mathrm{~K} / \mathrm{AKT}$ and JNK signaling pathways with down-regulation of MMP-2/9 expressions in prostate cancer PC-3 cells. Mol Cell Biochem 333: 169-180, 2010.

28 Pal HC, Sharma S, Strickland LR, Katiyar SK, Ballestas ME, Athar M, Elmets CA and Afaq F: Fisetin inhibits human melanoma cell invasion through promotion of mesenchymal to epithelial transition and by targeting MAPK and NFkappaB signaling pathways. PloS ONE 9: e86338, 2014.

29 Morrison DK: MAP kinase pathways. Cold Spring Harb Perspect Biol 42012.

30 Hemmings BA and Restuccia DF: PI3K-PKB/AKTpathway. Cold Spring Harb Perspect Biol 4: a011189, 2012.

31 Dai CX, Gao Q, Qiu SJ, Ju MJ, Cai MY, Xu YF, Zhou J, Zhang $\mathrm{BH}$ and Fan J: Hypoxia-inducible factor-1 alpha, in association with inflammation, angiogenesis and $\mathrm{MYC}$, is a critical prognostic factor in patients with $\mathrm{HCC}$ after surgery. BMC Cancer 9: 418, 2009

32 Khan SA, Thomas HC, Davidson BR and Taylor-Robinson SD: Cholangiocarcinoma. Lancet 366: 1303-1314, 2005.

33 Seehofer D, Kamphues C and Neuhaus P: Management of bile duct tumors. Exp Opin Pharmacother 9: 2843-2856, 2008.

34 de Groen PC, Gores GJ, LaRusso NF, Gunderson LL and Nagorney DM: Biliary tract cancers. N Engl J Med 341: 13681378,1999

35 Sever R and Brugge JS: Signal transduction in cancer. Cold Spring Harb Perspect Biol 5(4): pii: a006098, 2015.

36 Bacus SS, Gudkov AV, Lowe M, Lyass L, Yung Y, Komarov AP, Keyomarsi K, Yarden Y and Seger R: Taxol-induced apoptosis depends on MAP kinase pathways (ERK and p38) and is independent of p53. Oncogene 20: 147-155, 2001.

37 Tang D, Wu D, Hirao A, Lahti JM, Liu L, Mazza B, Kidd VJ, Mak TW and Ingram AJ: ERK activation mediates cell-cycle arrest and apoptosis after DNA damage independently of p53. J Biol Chem 277: 12710-12717, 2002.
38 Arai K, Lee SR, van Leyen $\mathrm{K}$, Kurose $\mathrm{H}$ and Lo EH: Involvement of ERK MAP kinase in endoplasmic reticulum stress in SH-SY5Y human neuroblastoma cells. J Neurochem 89: 232-239, 2004

$39 \mathrm{Hu}$ P, Han Z, Couvillon AD and Exton JH: Critical role of endogenous AKT/IAPs and MEK1/ERK pathways in counteracting endoplasmic reticulum stress-induced cell death. J Biol Chem 279: 49420-49429, 2004.

40 Marshall CJ: Specificity of receptor tyrosine kinase signaling: transient versus sustained extracellular signal-regulated kinase activation. Cell 80: 179-185, 1995.

41 Sewing A, Wiseman B, LLoyd AC and Land H: High-Intensity RAF signal causes cell-cycle arrest mediated by $\mathrm{p} 21^{\mathrm{cip} 1}$. Mol Cell Biol 17: 5588-5597, 1997.

42 Woods D, Parry D, Cherwinski H, Bosch E, Lees E and McMahon M: RAF-induced proliferation or cell-cycle arrest is determined by the level of RAF activity with arrest mediated by p21CIP1. Mol Cell Biol 17: 5598-5611, 1997.

43 Morgan MA, Parsels LA, Parsels JD, Mesiwala AK, Maybaum $\mathrm{J}$ and Lawrence TS: Role of checkpoint kinase 1 in preventing premature mitosis in response to gemcitabine. Cancer Res 65: 6835-6842, 2005.

44 Karnitz LM, Flatten KS, Wagner JM, Loegering D, Hackbarth JS, Arlander SJ, Vroman BT, Thomas MB, Baek YU, Hopkins KM, Lieberman HB, Chen J, Cliby WA and Kaufmann SH: Gemcitabine-induced activation of checkpoint signaling pathways that affect tumor cell survival. Mol Pharmacol 68: 1636-1644, 2005.

45 Matthews DJ, Yakes FM, Chen J, Tadano M, Bornheim L, Clary DO, Tai A, Wagner JM, Miller N, Kim YD, Robertson S, Murray L and Karnitz LM: Pharmacological abrogation of S-phase checkpoint enhances the antitumor activity of gemcitabine in vivo. Cell cycle 6: 104-110, 2007.
Received July 8, 2016

Revised July 28, 2016

Accepted August 1, 2016 